\title{
Accelerated lipid peroxidation in a rat model of gentamicin nephrotoxicity
}

\author{
ANAMARIA MAGDALENA TOMŞA ${ }^{1,2}$, ANDREEA LIANA RĂCHIŞAN ${ }^{1}$, STANCA LUCIA PANDREA $^{2,3}$, \\ ANDREEA BENEA $^{3}$, ANA UIFĂLEAN ${ }^{4}$, ALINA ELENA PARVU $^{4}$ and LIA MONICA JUNIE ${ }^{2}$ \\ ${ }^{1}$ Department 9-Mother and Child, Second Clinic of Pediatrics, 'Iuliu Haţieganu' University of Medicine and Pharmacy, \\ 400177 Cluj-Napoca; ${ }^{2}$ Department of Microbiology, 'Iuliu Haţieganu' University of Medicine and Pharmacy, \\ 400012 Cluj-Napoca; ${ }^{3}$ Laboratory Department, 'Prof. Dr. Octavian Fodor' Regional Institute of \\ Gastroenterology and Hepatology, 400162 Cluj-Napoca; ${ }^{4}$ Department of Pathophysiology, \\ 'Iuliu Haţieganu' University of Medicine and Pharmacy, 400012 Cluj-Napoca, Romania
}

Received July 2, 2021; Accepted August 3, 2021

DOI: $10.3892 / \mathrm{etm} .2021 .10652$

\begin{abstract}
Kidney disease represents a burden for the health care system worldwide. As the prevalence continues to rise, discovering new biomarkers of early kidney damage has become crucial. Oxidative stress (OS) represents one of the main factors involved in the early stages of many syndromes leading to kidney damage. Therefore, it must be studied in detail. To date, many studies have focused on OS in advanced stages of acute kidney injury (AKI), with great success. The aim of the present study was to ascertain whether even mild renal function impairment can be linked to specific systemic markers of OS and systemic antioxidants in order to pinpoint certain biomarkers for early kidney damage. We used male rats (Rattus norvegicus) in which we induced kidney damage by injecting gentamicin for 7 days. Blood was collected $24 \mathrm{~h}$ after the last dose of gentamicin. Urea, creatinine, 3-nitrotyrosine (3-NT), nitric oxide (NO), malondialdehyde (MDA), thiols (TS), total oxidative stress (TOS), and interferon- $\gamma($ IFN- $\gamma$ ) were determined. In addition, for the antioxidant status we measured total antioxidant capacity (TAC) and interleukin-10 (IL-10). Our results demonstrated that the rats had mild renal impairment consistent with a pre-AKI stage due to the nephrotoxic effect of gentamicin. However, TOS, MDA and NO were significantly higher in the gentamicin group compared to the control group. In addition, TAC was higher in the control group. Hence, OS
\end{abstract}

Correspondence to: Dr Anamaria Magdalena Tomşa, Department 9-Mother and Child, Second Clinic of Pediatrics, 'Iuliu Haţieganu' University of Medicine and Pharmacy, 8 Victor Babes Street, 400177 Cluj-Napoca, Romania

E-mail: anamariatomsa@icloud.com

Key words: oxidative stress, antioxidants, acute kidney injury, gentamicin, nephrotoxicity markers reach higher levels and may potentially be used as markers of kidney damage even in cases of mild renal function impairment.

\section{Introduction}

Acute deterioration of renal function translates into a syndrome known as acute kidney injury (AKI). The sudden drop in the glomerular filtration rate leads to the accumulation of the end products of creatinine and nitrogen metabolism in the blood. Diagnosing AKI relies greatly on determining the serum levels of these products, which causes a delay in emphasizing the kidney damage $(1,2)$.

Therefore, the need for earlier detection and better monitoring of these patients is vital. Oxidative stress (OS) is represented by reactive oxygen and nitrogen species (ROS, RNS) and free radicals that reach a level that exceeds the endogenous antioxidant capacity. OS is an important topic in research studies, and to date it has been declared a pathogenetic factor in many diseases (3-6). In the early stages of AKI there are changes and alterations in the structure and function of the mitochondria leading to ATP depletion and dysfunction in the energetic metabolism. Mitochondria are a major source of ROS, but they are also a source of antioxidant molecules (7-10). Despite the numerous studies that have focused on this topic, the precise mechanisms that generate reactive species (RS) in AKI continue to be unknown. Homeostasis is maintained by counteracting the physiological production of RS with a continuous endogenous production of antioxidants. Antioxidants usually intervene early in the development of AKI in order to scavenge RS, to downregulate OS and subsequently to reduce lipid peroxidation and total oxidative damage $(3,5,11)$.

The main purpose of the present study was to experimentally define the relationship between mild renal impairment (pre-AKI) and both the systemic OS and antioxidant status. In addition, we analyzed multiple markers in order to identify specific ones that could be further used to discover kidney injury at earlier stages. 


\section{Materials and methods}

Animals. A total of 14 adult male Rattus norvegicus rats, obtained from the Animal Facility of 'Iuliu Hatieganu' University of Medicine and Pharmacy, Cluj-Napoca, were used in this experiment (weighing, $400.07 \pm 56.04 \mathrm{~g}$ ). The animals were housed in standard cages equipped with wood chip bedding, in a room with an ambient temperature of $22 \pm 1^{\circ} \mathrm{C}$, a 12/12-h light/dark cycle, with 40-50\% humidity. Throughout the experiment, all animals were given ad libitum access to tap water and standard chow for rodents.

Experimental procedure. Rats were arbitrarily divided equally into two groups: The control group $(n=7)$ and the gentamicin group $(n=7)$. Total experiment time was 10 days. All rats were given 2 days to acclimatize to the environment before starting the injections. Rats in the control group were injected intraperitoneally (i.p.) with physiological saline solution for 7 consecutive days. Rats in the gentamicin group were injected i.p. with gentamicin for 7 consecutive days (KRKA D.D. Novo mesto, Slovenia, $60 \mathrm{mg} / \mathrm{kg} /$ day). The volume of physiological saline volume was equivalent to the volume of the gentamicin solution. For the collection of urine, rats were placed in metabolic cages (with ad libitum access to tap water) for $24 \mathrm{~h}: 2$ rats from each group between day 8 and 9 , and also 2 rats from each group between day 9 and 10 . Blood was collected $24 \mathrm{~h}$ after the last injection, by retro-orbital puncture. Animals were sacrificed by cervical dislocation. The blood was left undisturbed to coagulate for $1 \mathrm{~h}$ at $4^{\circ} \mathrm{C}$, then it was centrifuged at $1,730 \mathrm{x} \mathrm{g}$ for $15 \mathrm{~min}$ to obtain the serum. The serum was stored at $-20^{\circ} \mathrm{C}$ until further analysis.

Biochemical analysis. Serum concentrations of urea and creatinine were measured in order to determine renal function. The quantitative determination of urea (serum, urine) was made based on the principle of enzymatically hydrolyzation of urea into ammonia and carbon dioxide. Ammonia ions further react with $\alpha$-ketoglutarate and glutamate dehydrogenase (GLDH) with simultaneous oxidation of $\mathrm{NADH}$ to $\mathrm{NAD}^{+}$. The urea concentration in the sample was proportional to the decrease in concentration of NADH. The working reagent (WR) consisted of R1 buffer (Tris pH 7.8, $\alpha$-ketoglutarate, urease) mixed with R2 enzymes (GLDH, NADH), 4:1 (Urea-LQ, Spinreact). The absorbance was read at $340 \mathrm{~nm}$ at $30 \mathrm{sec}$ and $90 \mathrm{sec}$ after mixing the working reagent with the sample, at room temperature. To determine the urinary urea (urine $/ 24 \mathrm{~h}$ ), we used a 1:50 dilution with distilled water and followed the same steps as previously described $(12,13)$.

The quantitative determination of creatinine in serum and urine was determined utilizing an assay based on a reaction described by Jaffé in which creatinine reacts with sodium picrate, forming a red complex. The intensity of the color is proportional to the concentration of creatinine in the sample. The working reagent consisted of R1 picric acid and R2 sodium hydroxide, 1:1 (Creatinine-J, Spinreact). The reading was carried out at $492 \mathrm{~nm}$, at $30 \mathrm{sec}$ after the sample addition and again after $90 \mathrm{sec}$ (at room temperature). To determine the urinary concentration of creatinine, the sample (urine/24 h) was diluted with distilled water, 1:50, followed by the steps as described previously $(14,15)$.
OS analysis. Malondialdehyde (MDA), 3-nitrotyrosine (3-NT), interferon- $\gamma(\mathrm{IFN}-\gamma)$, nitric oxide (NO) and total oxidative stress (TOS) were measured to determine the level of OS.

The peroxidation of lipids was determined by reactive substances with thiobarbituric-reactive substances (TBARs), using an adapted procedure reported by Pasha and Sadasivadu (16). Thus, $0.1 \mathrm{ml}$ of serum was mixed with $0.1 \mathrm{ml} 40 \%$ TCO, which was further mixed with $0.2 \mathrm{ml}$ $0.67 \%$ TBA. The mix was placed in a boiling water bath for $30 \mathrm{~min}$, after which it was cooled in an ice water bath. After cooling, the mix was centrifuged for $5 \mathrm{~min}$ at $3,461 \mathrm{~g}$. Finally, $0.1 \mathrm{ml}$ of the supernatant was removed and subjected to reading at $530 \mathrm{~nm}$. TBAR values are expressed as MDA $\mathrm{nmol} / \mathrm{l}$.

3-NT was determined using the 3-NT ELISA Kit (Elabscience ${ }^{\circledR}$ ). An amount $50 \mu 1$ of the sample was added to each well, together with $50 \mu$ l of biotinylated detection $\mathrm{Ab}$ working solution, followed by incubation for $45 \mathrm{~min}$ at $37^{\circ} \mathrm{C}$. Afterwards, the plate was aspirated and washed for 3 times. HRP conjugate working solution $(100 \mu \mathrm{l})$ was then added, followed by incubation for $30 \mathrm{~min}$ at $37^{\circ} \mathrm{C}$. The plate was then aspirated and washed 5 times. Substrate reagent $(90 \mu \mathrm{l})$ was then added, followed by another incubation of $15 \mathrm{~min}$ at $37^{\circ} \mathrm{C}$. Finally, $50 \mu \mathrm{l}$ of stop solution was then added. The plate was immediately read at $450 \mathrm{~nm}$.

Serum concentration of IFN- $\gamma$ was measured using an ELISA Kit (Elabscience $\left.{ }^{\circledR}\right)$. Serum $(100 \mu \mathrm{l})$ was added to the wells, and then incubated for $90 \mathrm{~min}$ at $37^{\circ} \mathrm{C}$. The liquid was discarded, followed immediately by the addition of $100 \mu \mathrm{l}$ biotinylated detection $\mathrm{Ab}$ working solution to each well. Afterwards the plate was incubated for $60 \mathrm{~min}$ at $37^{\circ} \mathrm{C}$. The plate was aspirated and washed 3 times. HRP conjugate working solution $(100 \mu \mathrm{l})$ was then added, followed by incubation for $30 \mathrm{~min}$ at $37^{\circ} \mathrm{C}$. The plate was then aspirated and washed 5 times. Substrate reagent $(90 \mu \mathrm{l})$ was then added, followed by another incubation of $15 \mathrm{~min}$ at $37^{\circ} \mathrm{C}$. Finally, $50 \mu$ of stop solution was then added. The plate was immediately read at $450 \mathrm{~nm}$.

The serum concentration of $\mathrm{NO}$ was measured by a standard nitrate reduction and detection by the $\mathrm{VCl}_{3} / \mathrm{Griess}$ assay (17). A nitrate standard solution (100 $\mu \mathrm{l})$ was diluted from 200 to $1.6 \mu \mathrm{M}$, in duplicate, in a polystyrene microtiter plate with 96 flat-bottomed wells. The medium used for dilution was used as the standard blank. The 96-well plate was loaded with $100 \mu \mathrm{l}$ samples, then $\mathrm{VCl}_{3}$ was added to each well. Immediately after, Griess reagents, SULF (50 $\mu \mathrm{l})$ and NEDD $(50 \mu 1)$ were added. To obtain sample blank values, the diluting medium was substituted for Griess reagent. After $30 \mathrm{~min}$ of incubation at room temperature using $5 \% \mathrm{H}_{3} \mathrm{PO}_{4}(300 \mu \mathrm{l}$ total volume), the absorbance at $540 \mathrm{~nm}$ was measured. Results are expressed in $\mu \mathrm{mol} / 1$.

For the measurement of TOS, an assay calibrated with hydrogen peroxide was used, with results expressed in terms of micromolar hydrogen peroxide equivalent per liter $(\mu \mathrm{mol}$ $\left.\mathrm{H}_{2} \mathrm{O}_{2} \mathrm{Eq} / \mathrm{l}\right)$ (18). The preparation of $\mathrm{R} 1$ consisted in dissolving $114 \mathrm{mg}$ of xylenol orange and $8.18 \mathrm{~g}$ of $\mathrm{NaCl}$ in $900 \mathrm{ml}$ of $\mathrm{H}_{2} \mathrm{SO}_{4}$ solution, $25 \mathrm{mM}$. Glycerol was then added to the solution, $100 \mathrm{ml}$. The reagent had a $\mathrm{pH}$ value of 1.75 . For R2 $1.96 \mathrm{~g}$ of ferrous ammonium sulfate and $3.17 \mathrm{~g}$ of $o$-dianisidine dihydrochloride were dissolved in $1,000 \mathrm{ml}$ of $\mathrm{H}_{2} \mathrm{SO}_{4}$ solution, 
Table I. Characteristics of the control group (group 1, physiological saline) and the study group (group 2, gentamicin).

\begin{tabular}{lccc}
\hline Characteristics & Group 1 $(\mathrm{n}=7)$ & Group 2 $(\mathrm{n}=7)$ \\
Gentamicin group & P-value \\
\hline Initial body weight $(\mathrm{g})$ & $383.57 \pm 44.86$ & $416.57 \pm 64.47$ & NS \\
Final body weight $(\mathrm{g})$ & $388.57 \pm 47.60$ & $392.42 \pm 66.76$ & NS \\
Urine volume $(\mathrm{ml} / 24 \mathrm{~h})$ & $21.5 \pm 0.70^{\mathrm{a}}$ & $11 \pm 1.58^{\mathrm{b}}$ & $\mathbf{0 . 0 0 1}$ \\
\hline
\end{tabular}

${ }^{a} n=2 ;{ }^{b} n=4$. NS, not significant. Significant $P$-values are indicated in bold print.

$25 \mathrm{mM}$. R1 $(225 \mu \mathrm{l})$ was added to $35 \mu \mathrm{l}$ of serum. Then, $11 \mu \mathrm{l}$ of $\mathrm{R} 2$ was then added. The measurement was made at a $560 \mathrm{~nm}$ wavelength. The first absorbance was taken before the mixing of R1 and R2 (sample blank). The last absorbance was taken after the reaction trace drew a plateau line (3-4 min after mixing).

For the measurement of the serum levels of protein thiol groups (-SH) we used Ellman's reagent (19). Serum $(50 \mu \mathrm{l})$ was mixed with $1 \mathrm{ml}$ Tris $(0.25 \mathrm{M})$-EDTA $(20 \mathrm{mM})$, $\mathrm{pH} 8.2$. Afterwards, $20 \mu \mathrm{l}$ of DTNB $(10 \mathrm{mM})$ was added. After $15 \mathrm{~min}$ of incubation at room temperature, the measurement was made at $412 \mathrm{~nm}$. Results are expressed in $\mu \mathrm{mol} / 1$.

Antioxidant status analysis. The serum levels of interleukin-10 (IL-10) and total antioxidant capacity (TAC) were measured in order to evaluate the antioxidant capacity.

Serum IL-10 was determined using an ELISA Kit (Elabscience ${ }^{\circledR}$ ). Serum $100 \mu \mathrm{l}$ was added to the wells and incubated at $37^{\circ} \mathrm{C}$ for $90 \mathrm{~min}$. The liquid was then discarded, and then $100 \mu \mathrm{l}$ of biotinylated detection $\mathrm{Ab}$ working solution was added to each well, followed by $60 \mathrm{~min}$ of incubation at $37^{\circ} \mathrm{C}$. The plate was then aspirated and washed for 3 times. HRP conjugate working solution $(100 \mu \mathrm{l})$ was then added to each well, followed by another incubation at $37^{\circ} \mathrm{C}$ for $30 \mathrm{~min}$. The plate was aspirated and washed for 5 times. Substrate reagent was added, $90 \mu \mathrm{l}$, followed by incubation $\left(15 \mathrm{~min}, 37^{\circ} \mathrm{C}\right)$, and then by stop solution, $50 \mu \mathrm{l}$. The plate was immediately read at $450 \mathrm{~nm}$.

Serum TAC was measured using an automated measurement method, developed by Erel (20). R1 consisted of $o$-dianisidine $(10 \mathrm{mM})$ and ferrous ammonium sulfate $(45 \mu \mathrm{M})$ that were added in $\mathrm{KCl} / \mathrm{HCl}$ solution $(75 \mathrm{mM}, \mathrm{pH} 1.8)$. $\mathrm{R} 2$ consisted of $\mathrm{H}_{2} \mathrm{O}_{2}(7.5 \mathrm{mM})$. Serum $(5 \mu \mathrm{l})$ was mixed with $200 \mu \mathrm{l}$ of R1 and $10 \mu \mathrm{l}$ of R2. The measurement was made at $444 \mathrm{~nm}$. The first absorbance was taken before the mixing of R1 and R2 (sample blank). The last absorbance was taken at 3-4 min after the mixing with the serum. The results are expressed in mmol Trolox equivalent/1.

Statistical analysis. All results are presented as means \pm standard error of the mean value. Student's paired t-test was used for the analysis of experimental data with a Gaussian distribution. Data with non-Gaussian distribution were compared using the unpaired t-test. P-values $<0.05$ were considered statistically significant. Statistical analyses were performed using Excel and QI Macros package Windows ${ }^{\circledR} 2020$.

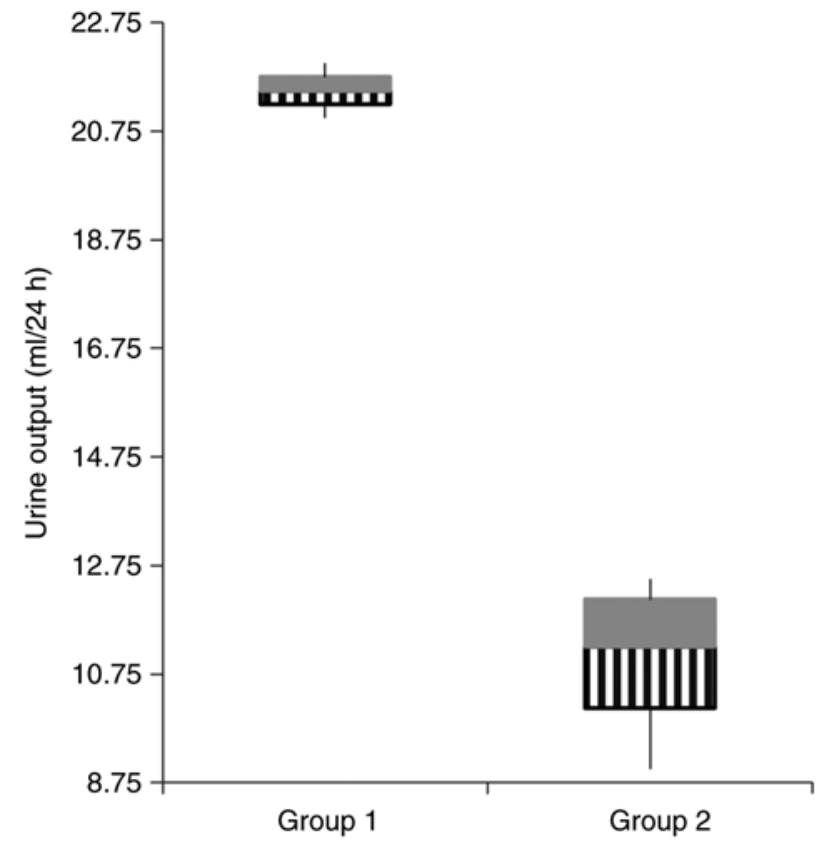

Figure 1. Box-plot showing the difference in the 24-h urine output between the control group (Group 1) and gentamicin group (Group 2) $\mathrm{P}=0.001$ ).

\section{Results}

The survival rate of the rats was $100 \%$ during the experimental procedures. The characteristics of our study groups are summarized in Table I. As Table I shows, there was no statistical difference between the two groups concerning body weight before and after the injection period, but a significant difference was observed in the $24 \mathrm{~h}$ urine output between the two groups (Fig. 1, $\mathrm{P}=0.001$ ).

There were significant differences between the two groups concerning the renal function parameters. The gentamicin group presented markedly elevated urea values in both blood and urine compared to the values of creatinine (Table II, Figs. 2 and 3).

OS parameters and antioxidant status were assessed in the two study groups and are summarized in Table III. Concerning the OS parameters, we observed a significant difference between the two groups for NO (Fig. 4), MDA (Fig. 5), but no statistical difference was obtained for 3-NT, thiols (TS) and IFN- $\gamma$.

In the gentamicin group TOS was found to be significantly higher compared to the control group (Fig. 6, $\mathrm{P}=0.03$ ). 
Table II. Renal function parameters (serum and urinary) in the study groups.

\begin{tabular}{lccc}
\hline & Group 1 $(\mathrm{n}=7)$ & Group 2 $(\mathrm{n}=7)$ & \\
Parameters & Control group & Gentamicin group & P-value \\
\hline Serum urea $(\mathrm{mg} / \mathrm{dl})$ & $44.57 \pm 6.84$ & $56.25 \pm 5.67$ & $\mathbf{< . 0 0 0 1}$ \\
Serum creatinine $(\mathrm{mg} / \mathrm{dl})$ & $0.77 \pm 0.001$ & $0.88 \pm 0.01$ & $\mathbf{0 . 0 2 0}$ \\
Urinary urea $(\mathrm{mg} / \mathrm{dl})$ & $346.66 \pm 2,403.55$ & $632.66 \pm 4,306.37$ & $\mathbf{0 . 0 1 3}$ \\
Urinary creatinine $(\mathrm{mg} / \mathrm{dl})$ & $35.01 \pm 2.47$ & $47.09 \pm 130.19$ & NS \\
\hline
\end{tabular}

NS, not significant. Significant P-values are indicated in bold print.

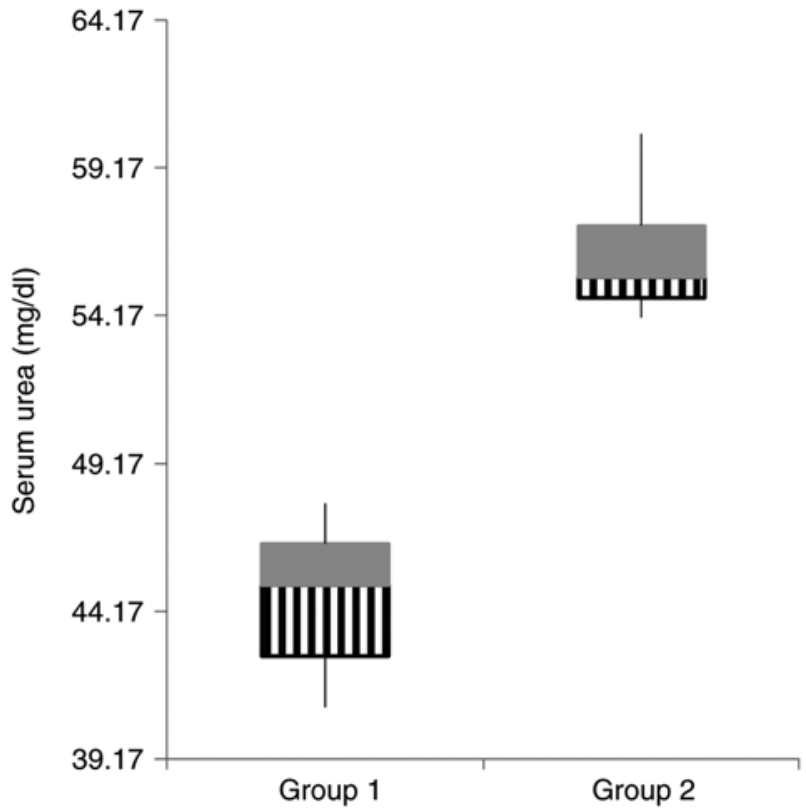

Figure 2. Box-plot showing the difference between the values of serum urea in the control group (Group 1) and gentamicin group (Group 2) $(\mathrm{P}<0.05)$.

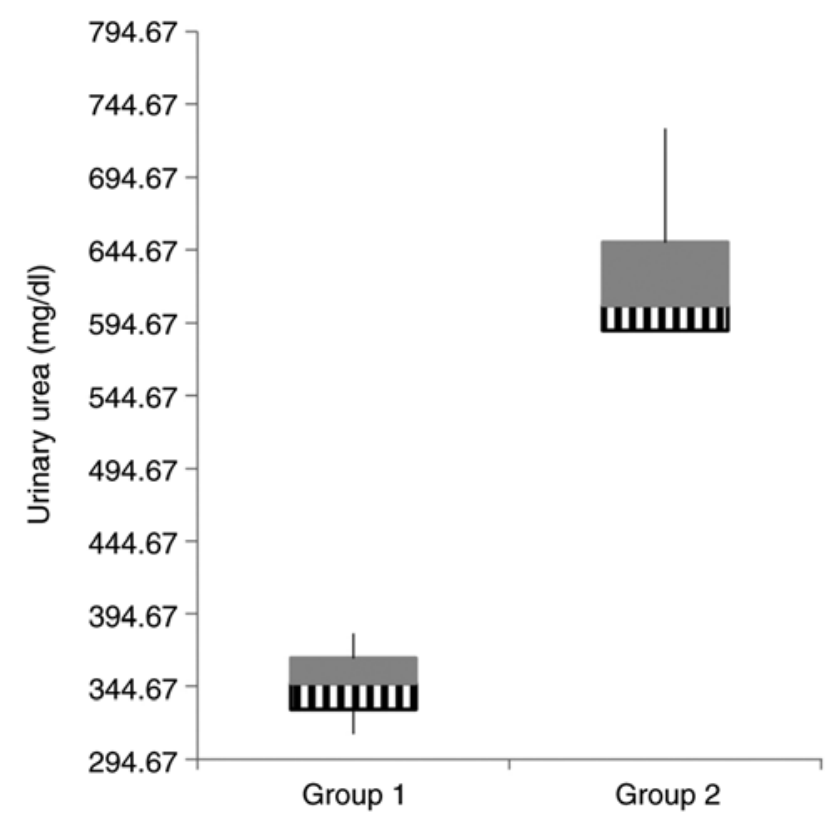

Figure 3. Box-plot showing the difference between the values of urinary urea in the control group (Group 1) and gentamicin group (Group 2) $(\mathrm{P}=0.013)$.

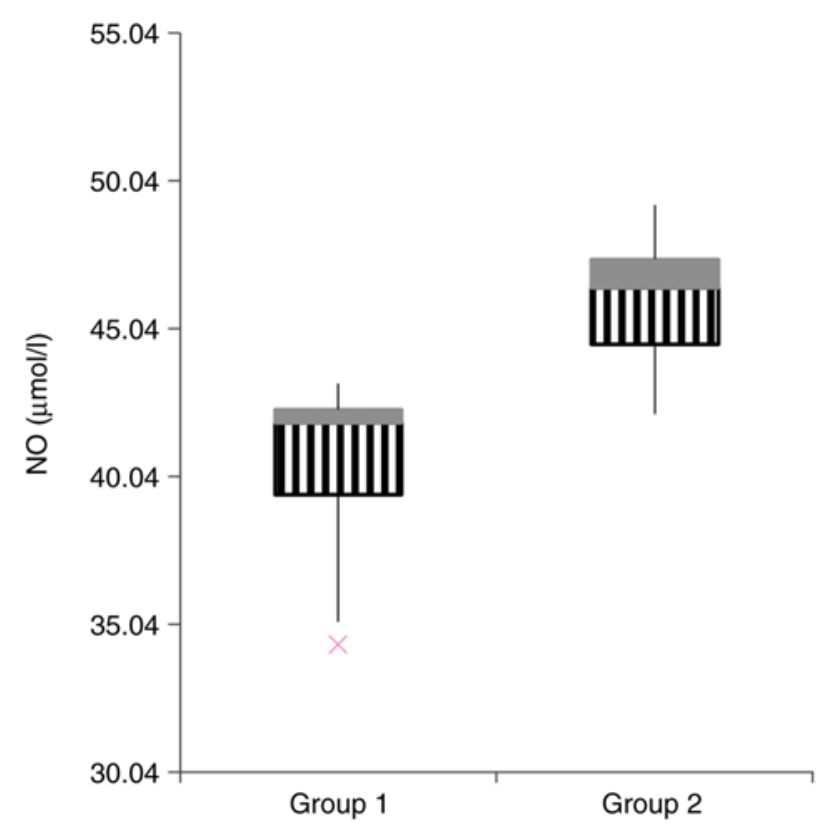

Figure 4. Box-plot showing the difference between the values of serum nitric oxide (NO) in the control group (Group 1) and gentamicin group (Group 2) ( $\mathrm{P}=0.01)$.

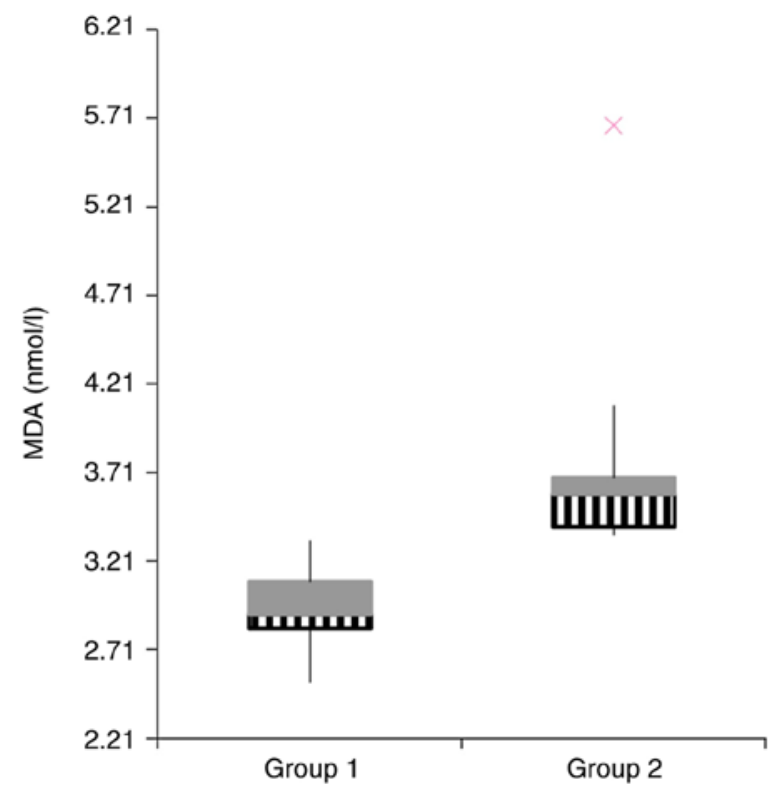

Figure 5. Box-plot showing the difference between the values of serum malondialdehyde (MDA) in the control group (Group 1) and gentamicin group (Group 2) $(\mathrm{P}=0.01)$. 
Table III. Oxidative stress parameters and antioxidant status in the study groups.

\begin{tabular}{lccc}
\hline Parameters & $\begin{array}{c}\text { Group 1 }(\mathrm{n}=7) \\
\text { Control group }\end{array}$ & $\begin{array}{c}\text { Group 2 }(\mathrm{n}=7) \\
\text { Gentamicin group }\end{array}$ & P-value \\
\hline 3-NT $(\mathrm{ng} / \mathrm{ml})$ & $19.53 \pm 32.67$ & $28.87 \pm 701.46$ & NS \\
NO $(\mu \mathrm{mol} / \mathrm{l})$ & $40.40 \pm 9.30$ & $45.94 \pm 5.93$ & $\mathbf{0 . 0 1}$ \\
MDA $(\mathrm{nmol} / \mathrm{l})$ & $2.94 \pm 0.068$ & $3.82 \pm 0.67$ & $\mathbf{0 . 0 1}$ \\
Thiols $(\mu \mathrm{mol} / \mathrm{l})$ & $394.14 \pm 3334.47$ & $322.42 \pm 267.61$ & NS \\
IFN- $\gamma(\mathrm{pg} / \mathrm{ml})$ & $24.27 \pm 45.71$ & $19.97 \pm 8.30$ & NS \\
TOS $\left(\mu \mathrm{mol} \mathrm{H} \mathrm{O}_{2} \mathrm{Eq} / \mathrm{l}\right)$ & $21.98 \pm 5.91$ & $25.05 \pm 5.04$ & $\mathbf{0 . 0 3}$ \\
IL-10 $(\mathrm{pg} / \mathrm{ml})$ & $15.81 \pm 16.12$ & $13.57 \pm 0.44$ & NS \\
TAC $(\mathrm{mmol} \mathrm{Trolox} \mathrm{Eq/l)}$ & $1.09 \pm 1.04$ & $1.09 \pm 4.81$ & $\mathbf{0 . 0 0 1}$ \\
OSI $(\mathrm{TOS} / \mathrm{TAC})$ & $20.05 \pm 4.91$ & $22.90 \pm 4.20$ & $\mathbf{0 . 0 1 4}$ \\
\hline
\end{tabular}

3-NT, 3-nitrotyrosine; NO, nitric oxide; MDA, malondialdehyde; IFN- $\gamma$, interferon- $\gamma$; TOS, total oxidative stress; IL, interleukin; TAC, total antioxidant capacity; OSI, oxidative stress index. NS, not significant. Significant P-values are indicated in bold print.

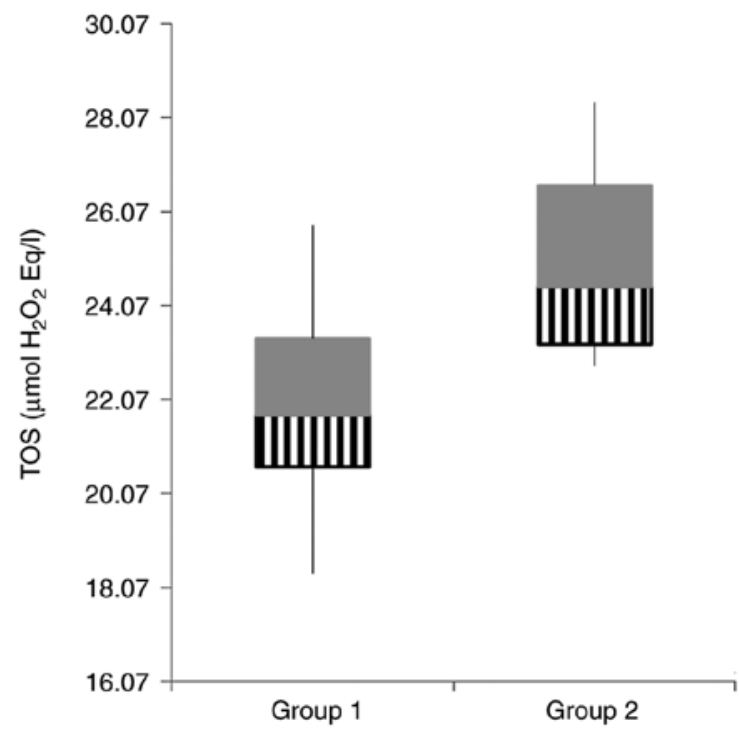

Figure 6. Box-plot showing the difference between the values of serum total oxidative stress (TOS) in the control group (Group 1) and gentamicin group (Group 2) $(\mathrm{P}=0.03)$.

The antioxidant status was evaluated using IL-10 and TAC, with TAC being statistically higher in the control group (Fig. 7). Oxidative stress index (OSI) was significantly higher in the gentamicin group compared to the control group $(\mathrm{P}=0.014)$.

\section{Discussion}

In the present study, we were able to induce a mild form of renal function impairment by injecting gentamicin (60 mg/kg/day, i.p.) for 7 consecutive days, as shown by the reduced urine output in the gentamicin group, correlated with increased serum values of both urea and creatinine. In addition, even though it was not statistically significant, a decrease in the weight of the rats in the gentamicin group was observed. These findings are in line with previous studies conducted on rats with kidney injury induced by gentamicin (21-23).

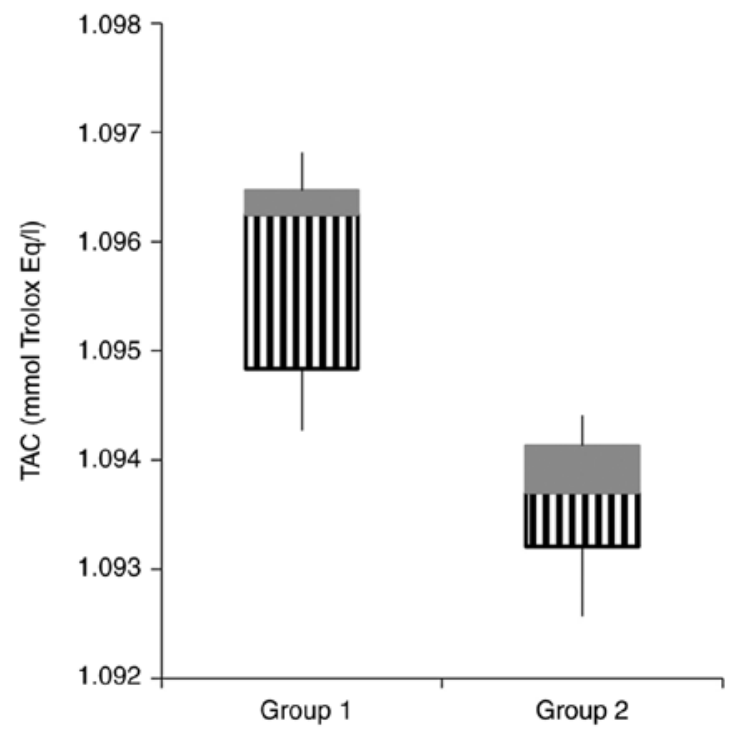

Figure 7. Box-plot showing the difference between the values of serum total antioxidant capacity (TAC) in the control group (Group 1) and gentamicin group (Group 2) $\mathrm{P}=0.001)$.

However, due to the fact that our animals received a smaller dose of gentamicin compared to the rats in the previously mentioned studies who received $100 \mathrm{mg} / \mathrm{kg} / \mathrm{day}$, the creatinine level was increased only 1.14 -fold compared to the control group, showing that our animals did not achieve stage I AKI (a 1.5-fold increase was needed). However, our results showed a greater increase in the urea values compared to the values of creatinine, both in serum (1.26-fold vs. 1.14-fold) and in urine (1.82-fold vs. 1.34-fold). Increased serum levels of urea might also be due to dehydration, heart failure, gastrointestinal bleeding, high-protein diet or catabolic state, but in our case these criteria were not met, since the only difference between our groups was the administration of gentamicin (24). Therefore, in our study, the differences in the urea values were due to an impairment in renal function, secondary to the nephrotoxic effect of gentamicin. Our result confirmed that urea reaches higher concentrations faster than creatinine. The 
accumulation of these end products in the blood demonstrated that gentamicin exerted a nephrotoxic effect on our rats, with mild renal function impairment, consistent with a pre-AKI stage.

With regard to TOS, it proved to be higher in the gentamicin group compared to the control group, which was corelates with an OSI which was also higher in the same group. Furthermore, we were able to identify two OS markers that were significantly higher in the group receiving gentamicin: NO and MDA.

NO production takes place in reaction to an inflammatory stimulus and can be triggered by increased levels of IFN- $\gamma$, tumor necrosis factor (TNF)- $\alpha$, and IL-1 $\beta$ (25). Larger levels of NO produce NO-derived reactive species that can further nitrosate TS. Previous studies have shown that NO represents a marker of OS that is upregulated in AKI (26-29). Pathak and Mayeux used an animal model of sepsis-induced kidney injury and showed that the generation of NO significantly increased compared to the control group (26). In accordance with these results, in our case, NO reached significantly higher serum levels after gentamicin administration compared to the control group, in spite of the rats in this group not having fully achieved stage I of AKI. This confirms that NO may play a crucial role in the early diagnosis of kidney damage or it may be used as a marker of nephrotoxicity.

MDA has been accepted as a reliable marker of OS, as it represents one of the lipid peroxidation products (30). In our study, MDA was 1.29-fold higher in rats with exposure to gentamicin compared to the control. In comparison, $\mathrm{Su}$ et al confirmed that Panxl-knockout mice had decreased MDA levels in kidney tissues when subjected to ischemic AKI compared to wild-type mice, which further demonstrates that MDA plays a pathogenetic role in AKI (31). Awodele et al conducted a study demonstrating that MDA is significantly increased in rats receiving gentamicin compared to the controls. They concluded that the mechanism of toxicity caused by gentamicin was via OS and subsequent lipid peroxidation (32). Lipid peroxidation was also demonstrated in an animal model of kidney injury induced by cisplatin (33). Kovalčíková et al showed that AKI leads to increased systemic OS, but they also demonstrated increased lipid oxidation markers in the frontal cortex that may explain uremic encephalopathy (34). These data show that lipid peroxidation is consistent in kidney damage, and MDA can be used as a marker in AKI.

However, 3-NT, TS and IFN- $\gamma$ were confirmed to have similar concentrations in the serum of the two groups. In contrast, there are experimental and clinical studies that show a higher concentration of these markers in subjects with AKI compared to the control. One study included 158 patients with AKI and found that 3-NT was significantly higher in those subjects compared to healthy controls and to critically ill subjects without AKI $(\mathrm{P}<0.001)$, concluding that 3 -NT levels are associated with mortality of patients with AKI, independent of the gravity of the disease (35). TS were also previously associated with AKI, as Boekhoud et al confirmed in their study conducted on 301 critically ill patients (36). Burks et al extensively investigated the effects of pulsed focused ultrasound (pFUS) on mesenchymal stem cells (MSCs) in mice with cisplatin-induced AKI. They demonstrated that following the infusion of cisplatin and subsequent AKI, pFUS was able to upregulate renal IFN- $\gamma$ which further stimulated MSCs that were subsequently infused to upregulate IL-10 and therefore to promote healing (37). Even though IFN- $\gamma$ represents an OS marker, they showed that the IFN- $\gamma / \mathrm{IL}-10$ cytokine axis plays an essential role in the outcome of AKI (38).

In the present study, IL-10 had similar concentrations in the serums of the two groups. In contrast, IL-10 proved to reduce injury in several models of AKI (39-44). Our results may be due to the fact that our rats did not achieve stage I of AKI. It is to be mentioned that IL-10 was 1.16-fold higher in the control group compared to gentamicin group, with a P-value of 0.09 .

TAC was significantly higher in the control group compared to the pre-AKI group, which further demonstrates that the nephrotoxic effect of gentamicin impairs the oxidant-antioxidant balance, in favour of OS.

One limitation of our study is represented by the fact that we could not verify the renal parameters of the gentamicin group before injecting the nephrotoxic drug. In addition, another limitation is given by the fact that we were not able to collect urine from all of our animals due to a limited number of metabolic cages available; therefore, we could not calculate the precise glomerular filtration rate of the animals.

In conclusion, our study demonstrated that the oxidant-antioxidant balance is impaired in favour of OS in renal damage induced by gentamicin, a nephrotoxic drug. In addition, it provides strong evidence that lipid peroxidation plays a crucial role in gentamicin nephrotoxicity. Moreover, MDA and NO may be used as markers of early kidney damage when changes in serum creatinine are not yet fully relevant. The novelty brought by this study is represented by the fact that our animals suffered only mild renal impairment, in contrast with other experimental studies where the animals achieved different stages of AKI. Even so, we were able to pinpoint certain OS markers that were significantly modified in the gentamicin group compared to the control group. More studies are needed in order to validate these markers in other types of AKI (ischemic, sepsis-induced).

\section{Acknowledgements}

We would like to acknowledge Mr. Mirel Molnar (Department of Pathophysiology) for his essential work as a laboratory technician.

\section{Funding}

Anamaria Magdalena Tomşa is the recipient of an internal grant from 'Iuliu Hatieganu' University of Medicine and Pharmacy, Cluj-Napoca, Romania. This study was funded by this grant.

\section{Availability of data and materials}

All data analyzed during this study are included in this published article.

\section{Authors' contributions}

AMT, ALR, LMJ and AEP conceived the experimental protocol. AMT performed the in vivo experiment. SLP, 
$\mathrm{AB}$ and $\mathrm{AU}$ performed the measurements. AMT and ALR analyzed the data and prepared the manuscript. LMJ and AEP performed the critical revision of the manuscript. All authors read and approved the manuscript and agree to be accountable for all aspects of the research in ensuring that the accuracy or integrity of any part of the work are appropriately investigated and resolved.

\section{Ethics approval and consent to participate}

This study was approved by the Ethics Committee of the 'Iuliu Hatieganu' University of Medicine and Pharmacy, Cluj-Napoca, Romania (authorization no. 193/18.05.2020). This study was also approved by The National Sanitary Veterinary and Food Safety Authority (authorization no. 225/22.06.2020). This study was carried out according to relevant national legislation.

\section{Patient consent for publication}

Not applicable.

\section{Competing interests}

The authors state that they have no competing interests.

\section{References}

1. Susantitaphong P, Cruz DN, Cerda J, Abulfaraj M, Alqahtani F, Koulouridis I and Jaber BL; Acute Kidney Injury Advisory Group of the American Society of Nephrology: World incidence of AKI: A meta-analysis. Clin J Am Soc Nephrol 8: 1482-1493, 2013.

2. Bellomo R, Kellum JA and Ronco C: Acute kidney injury. Lancet 380: 756-766, 2012.

3. Singh A, Kukreti R, Saso L and Kukreti S: Oxidative stress: A key modulator in neurodegenerative diseases. Molecules 24 $1583,2019$.

4. Himmelfarb J, McMonagle E, Freedman S, Klenzak J, McMenamin E, Le P, Pupim LB and Ikizler TA; The PICARD Group: Oxidative stress is increased in critically ill patients with acute renal failure. J Am Soc Nephrol 15: 2449-2456, 2004.

5. Ratliff BB, Abdulmahdi W, Pawar R and Wolin MS: Oxidant mechanisms in renal injury and disease. Antioxid Redox Signal 25: 119-146, 2016.

6. Schieber M and Chandel NS: ROS function in redox signaling and oxidative stress. Current Biology 24: R453-R462, 2014.

7. Sureshbabu A, Ryter SW and Choi ME: Oxidative stress and autophagy: Crucial modulators of kidney injury. Redox Biol 4 208-214, 2015

8. Hall AM, Rhodes GJ, Sandoval RM, Corridon PR and Molitoris BA: In vivo multiphoton imaging of mitochondrial structure and function during acute kidney injury. Kidney Int 83 : 72-83, 2013.

9. Tanaka S, Tanaka T, Kawakami T, Takano H, Sugahara M, Saito H, Higashijima Y, Yamaguchi J, Inagi R and Nangaku M: Vascular adhesion protein-1 enhances neutrophil infiltration by generation of hydrogen peroxide in renal ischemia/reperfusion injury. Kidney International 92: 154-164, 2017.

10. Tracz MJ, Juncos JP, Croatt AJ, Ackerman AW, Grande JP, Knutson KL, Kane GC, Terzic A, Griffin MD and Nath KA: Deficiency of heme oxygenase-1 impairs renal hemodynamics and exaggerates systemic inflammatory responses to renal ischemia. Kidney Int 72: 1073-1080, 2007.

11. Dennis JM and Witting PK: Protective role for antioxidants in acute kidney disease. Nutrients 9: 718, 2017.

12. Kaplan A: Urea. In: Clinical Chemistry. CV Mosby Co., St Louis. Princeton, Toronto, pp1257-1260 and 437 and 418, 1984.

13. Burtis AC and Ashwood ER: Tietz Textbook of Clinical Chemistry. 3rd edition. Saunders, Philadelphia, PA, 1999.
14. Murray RL: Creatinine. In: Clinical Chemistry. CV Mosby Co., St Louis. Princeton, Toronto, pp1261-1266 and 418, 1984.

15. Young DS: Effects of disease on Clinical Lab Tests. 4th edition. AACC, Washington, DC, 2001

16. Pasha KV and Sadasivudu B: Intracellular content of thiol compounds, thiobarbituric acid reactive substances and gamma-glutamyl transpeptidase in rat brain during anoxia. Neurosci Lett 46: 209-214, 1984

17. Miranda MK, Espey GM and Wink AD: A rapid, simple spectrophotometric method for simultaneous detection of nitrate and nitrite. Nitric Oxide 5: 62-71, 2001

18. Erel O: A new automated colorimetric method for measuring total oxidant status. Clin Biochem 38: 1103-1111, 2005.

19. Hu ML: Measurement of protein thiol groups and glutathione in plasma. Methods Enzymol 233: 380-384, 1994.

20. Erel O: A novel automated direct measurement method for total antioxidant capacity using a new generation, more stable ABTS radical cation. Clin Biochem 37: 277-285, 2004.

21. Erdem A, Gündoğan NU, Usubütün A, Kilinç K, Erdem SR, Kara A and Bozkurt A: The protective effect of taurine against gentamicin-induced acute tubular necrosis in rats. Nephrol Dial Transplant 15: 1175-1182, 2000.

22. Medić B, Stojanović M, Rovčanin B, Kekić D, Škodrić SR, Jovanović GB, Vujović KS, Divac N, Stojanović R, Radenković M, et al: Pioglitazone attenuates kidney injury in an experimental model of gentamicin-induced nephrotoxicity in rats. Sci Rep Sep 9: 13689, 2019.

23. Sodimbaku V, Pujari L, Mullangi R and Marri S: Carrot (Daucus carota L.): Nephroprotective against gentamicin-induced nephrotoxicity in rats. Indian J Pharmacol. 48: 122-127, 2016.

24. Weiner ID, Mitch WE and Sands JM: Urea and ammonia metabolism and the control of renal nitrogen excretion. Clin J Am Soc Nephrol 10: 1444-1458, 2015.

25. McSorley SJ and Liew FY: Nitric oxide. In: Encyclopedia of Immunology. 2nd edition. Elsevier, Berkeley, CA, pp1859-1861, 1998.

26. Pathak E and Mayeux PR: In vitro model of sepsis-induced renal epithelial reactive nitrogen species generation. Toxicol Sci 115: 475-481, 2010.

27. Pathak E, MacMillan-Crow LA and Mayeux PR: Role of mitochondrial oxidants in an in vitro model of sepsis-induced renal injury. J Pharmacol Exp Ther 340: 192-201, 2012.

28. Tomsa AM, Alexa AL, Junie ML, Rachisan AL and Ciumarnean L: Oxidative stress as a potential target in acute kidney injury. PeerJ 7: e8046, 2019.

29. Ling H, Edelstein C, Gengaro P, Meng X, Lucia S, Knotek M, Wangsiripaisan A, Shi Y and Schrier R: Attenuation of renal ischemia-reperfusion injury in inducible nitric oxide synthase knockout mice. Am J Physiol 277: F383-F390, 1999.

30. Mitev D, Gradeva H, Stoyanova Z, Petrova N, Dimov D, Iliev V, Koychev A, Prakova G and Vlaykova T: Evaluation of thiol compounds and lipid peroxidative products in plasma of patients with COPD. Trakia J Sci 8: 306-314, 2010.

31. Su L, Jiang X, Yang C, Zhang J, Chen B, Li Y, Yao S, Xie Q, Gomez H, Murugan R and Peng Z: Pannexin 1 mediates ferroptosis that contributes to renal ischemia/reperfusion injury. J Biol Chem 294: 19395-19404, 2019.

32. Awodele O, Tomoye OP, Quashie NB, Amagon KI and Ogunnowo SA: Gentamicin nephrotoxicity: Animal experimental correlate with human pharmacovigilance outcome. Biomed J 38: 125-130, 2015.

33. Mata-Miranda MM, Bernal-Barquero CE, Martinez-Cuazitl A, Guerrero-Robles CI, Sanchez-Monroy V, Rojas-Lopez M and Vazquez-Zapien GJ: Nephroprotective effect of embryonic stem cells reducing lipid peroxidation in kidney injury induced by cisplatin. Oxid Med Cell Longev 2019: 5420624 2019.

34. Kovalčíková A, Gyurászová M, Vavrincová-Yaghi D, Vavrinec $\mathrm{P}$, Tóthová L, Boor P, Šebeková K and Celec P: Oxidative stress in the brain caused by acute kidney injury. Metab Brain Dis 33: 961-967, 2018.

35. Qian J, You H, Zhu Q, Ma S, Zhou Y, Zheng Y, Liu J, Kuang D, $\mathrm{Gu}$ Y, Hao C and Ding F: Nitrotyrosine level was associated with mortality in patients with acute kidney injury. PLoS One 8: e79962, 2013

36. Boekhoud L, Koeze J, van der Slikke EC, Bourgonje AR, Moser J, Zijlstra JG, Muller Kobold AC, Bulthuis MLC, van Meurs M, van Goor H and Bouma HR: Acute kidney injury is associated with lowered plasma-free thiol levels. Antioxidants (Basel) 9: 1135,2020 
37. Burks SR, Nagle ME, Bresler MN, Kim SJ, Star RA and Frank JA Mesenchymal stromal cell potency to treat acute kidney injury increased by ultrasound-activated interferon- $\gamma /$ interleukin- 10 axis. J Cell Mol Med 22: 6015-6025, 2018.

38. Hubackova S, Kucerova A, Michlits G, Kyjacova L, Reinis M, Korolov O, Bartek J and Hodny Z: IFN $\gamma$ induces oxidative stress, DNA damage and tumor cell senescence via TGF $\beta / S M A D$ signaling-dependent induction of Nox4 and suppression of ANT2. Oncogene 35: 1236-1249, 2016

39. Deng J, Kohda Y, Chiao H, Wang Y, Hu X, Hewitt SM, Miyaji T, McLeroy P, Nibhanupudy B, Li S and Star RA: Interleukin-10 inhibits ischemic and cisplatin-induced acute renal injury. Kidney Int 60: 2118-2128, 2001.

40. Jung M, Sola A, Hughes J, Kluth DC, Vinuesa E, Viñas JL, Pérez-Ladaga A and Hotter G: Infusion of IL-10-expressing cells protects against renal ischemia through induction of lipocalin-2. Kidney Int 81: 969-982, 2012.
41. Wise AF, Williams TM, Kiewiet MB, Payne NL, Siatskas C, Samuel CS and Ricardo SD: Human mesenchymal stem cells alter macrophage phenotype and promote regeneration via homing to the kidney following ischemia-reperfusion injury. Am J Physiol Renal Physiol 306: F1222-F1235, 2014.

42. Tomşa AM, Picoş A, Picoş AM and Răchişan AL: Mitochondrial nanotargeting in malignancies (Review). Exp Ther Med 20: 3444-3451, 2020

43. Tomşa AM, Răchişan AL, Aldea AA and Ciumărnean L: Perspectives of gold nanoparticles and their applications in pancreatic cancer (Review). Exp Ther Med 21: 258, 2021.

44. Xia Y, Chen Y, Tang L, Wang Z and Zheng Y: Pterostilbene attenuates acute kidney injury in septic mice. Exp Ther Med 15: 3551-3555, 2018. 